\title{
Deletion and Replacement of the Mouse Adult $\beta$-Globin Genes by a "Plug and Socket" Repeated Targeting Strategy
}

\author{
PETER J. DETLOFF,${ }^{1} \dagger$ JADA LEWIS, ${ }^{1}$ SIMON W. M. JOHN,${ }^{1}$ W. RONALD SHEHEE, ${ }^{2}$ \\ ROBERT LANGENBACH ${ }^{3}$ NOBUYO MAEDA, ${ }^{1}$ AND OLIVER SMITHIES ${ }^{1 *}$ \\ Department of Pathology, University of North Carolina, Chapel Hill, North Carolina 27599, ${ }^{1}$ and Departments \\ of Biochemistry and Cell Biology, Glaxo Research Institute, ${ }^{2}$ and Laboratory of Experimental \\ Carcinogenesis and Mutagenesis, National Institute of Environmental Health \\ Sciences, ${ }^{3}$ Research Triangle Park, North Carolina 27709
}

Received 20 April 1994/Returned for modification 14 June 1994/Accepted 19 July 1994

\begin{abstract}
We describe a two-step strategy to alter any mouse locus repeatedly and efficiently by direct positive selection. Using conventional targeting for the first step, a functional neo gene and a nonfunctional HPRT minigene (the "socket") are introduced into the genome of HPRT" ${ }^{-}$embryonic stem (ES) cells close to the chosen locus, in this case the $\beta$-globin locus. For the second step, a targeting construct (the "plug") that recombines homologously with the integrated socket and supplies the remaining portion of the $H P R T$ minigene is used; this homologous recombination generates a functional HPRT gene and makes the ES cells hypoxanthine-aminopterin-thymidine resistant. At the same time, the plug provides DNA sequences that recombine homologously with sequences in the target locus and modifies them in the desired manner; the plug is designed so that correctly targeted cells also lose the neo gene and become G418 sensitive. We have used two different plugs to make alterations in the mouse $\beta$-globin locus starting with the same socket-containing ES cell line. One plug deleted $20 \mathrm{~kb}$ of DNA containing the two adult $\beta$-globin genes. The other replaced the same region with the human $\beta$-globin gene containing the mutation responsible for sickle cell anemia.
\end{abstract}

Gene targeting in embryonic stem (ES) cells has made possible the construction of mice with predetermined mutations, including null mutations in many genes associated with human disease. Many genetic disorders, however, are not due to null mutations. In fact, at many disease-associated loci, the diversity of mutations causes a similar diversity in symptoms. For example, different mutations in the $\beta$-globin locus cause congenital Heinz body hemolytic anemia, familial cyanosis, sickle cell anemia, and thalassemias varying in severity (25). Mutational diversity consequently poses a challenge in designing mouse models of human disease, since each mutation must be targeted to the same locus as a separate recombination event.

Conventional gene targeting involves positively selecting cells that have incorporated exogenous DNA, which includes a selectable marker such as the neo gene linked to sequences homologous to the target locus, followed by screening these transformants for cells in which the desired homologous recombination event has occurred (21). For some recombination events, thousands of colonies may have to be screened to find those that are targeted $(10,19)$, although the number can often be reduced by adding a negatively selectable marker such as the herpes simplex virus (HSV) $t k$ gene to the construct (14). Altering a gene in many different ways by these procedures requires repeating the selection and screening for each modification. Strategies have therefore been devised to eliminate the repeated screening $(1,22,26)$. For example, Askew et al. (1) used a two-step method to repeatedly modify the $\alpha 2-\mathrm{Na}, \mathrm{K}$ ATPase gene. In the first step, both the neo and HSV $t k$ genes were inserted into the target locus by conventional gene targeting. In the second step, the target gene was modified by

\footnotetext{
${ }^{*}$ Corresponding author.

† Present address: Department of Biochemistry and Molecular Genetics, University of Alabama, Birmingham, AL 35294.
}

a second targeting event using a construct designed to introduce a mutation while simultaneously removing the HSV $t k$ gene. This second targeting step theoretically requires only negative selection against the inserted marker, which can be repeated easily. In practice, however, the second step may involve more screening than the first because of a high background of nontargeted cells that spontaneously lose expression of the negatively selectable marker. Loss of marker function can occur (i) by recombination, (ii) by inactivation (e.g., methylation or mutation), or (iii) by nondisjunction. The incidence of background colonies therefore depends upon the number of cell divisions taking place between any type of spontaneous loss of the marker function and the loss of marker function due to the second targeting event. Unless a selection scheme is used to avoid their survival, background mutants will consequently accumulate during the cell expansion between the two targeting events. If spontaneous loss of the marker function occurs in a cell 10 generations prior to the second targeting, this one event will result in 1,024 $\left(2^{10}\right)$ background colonies. If the loss occurs three generations prior to the second targeting, there will be $8\left(2^{3}\right)$ background colonies. This phenomenon was first described by Luria and Delbruck in 1943, who termed it fluctuation, since it causes the number of background colonies to fluctuate widely from experiment to experiment (12). Strategies relying on negative selection for loss of function in ES cells are therefore likely to exhibit wide fluctuations in the numbers of background colonies.

We have devised a two-step targeting strategy that eliminates the problems associated with background colonies. Unplanned losses of marker function and fluctuation problems are both avoided by using positive rather than negative selection for the second step and by designing the system so that the positively selectable marker cannot spontaneously become functional. The first step in our "plug and socket" strategy uses conventional targeting to introduce a nonfunctional portion of the selectable marker (the "socket") close to the chosen locus. 
The second step modifies the locus by homologous recombination with a targeting construct (the "plug") designed to have two functions. First, the plug modifies the target gene in the desired manner. Second, the plug recombines with the nonfunctional marker and converts it into a functional form. The plug and the socket are designed to contain different nonrevertible mutations (deletions) in the marker gene. Consequently restoration of function is absolutely dependent upon homologous recombination. Furthermore, since the plug and socket steps are independent, one ES cell line with an appropriate socket can be transformed repeatedly with a variety of plugs using direct positive selection.

We here describe using the plug and socket system to repeatedly modify the mouse $\beta$-globin locus. First, an ES cell line was made by targeting a socket to the $\beta$-globin locus. Two different plugs were then used to make two different modifications in the same socket-containing cell line. The first plug deleted a $20-\mathrm{kb}$ portion of mouse chromosome 7 containing the two adult $\beta$-globin genes. The second plug replaced this region with the human $\beta$-globin variant responsible for sickle cell anemia $\left(\beta^{\mathrm{s}}\right)$.

\section{MATERIALS AND METHODS}

Cloning and plasmids. A conventional targeting construct, $\Delta \beta C$, contains a $0.8-\mathrm{kb}$ HindIII-Bam HI fragment that includes exon 1 of the $\beta^{\text {maj }}$ gene and a 3.9-kb HindIII fragment from downstream of the $\beta^{\text {min }}$ gene, with both fragments being from BALB/c mouse DNA. The mouse DNA fragments were flanked by two HSV $t k$ genes (14) and were separated by the neo gene (a 1.1-kb fragment of pMC1NeopA [24]).

The socket targeting construct, $\beta$ socket (see Fig. 2), was made from DNA isolated from the ES cell strain E14TG2a by screening a phage genomic fragment library (made by partial digestion with Sau3A) with a probe for $\beta^{\mathrm{min}}$. Two fragments were inserted into the $8.0-\mathrm{kb}$ fragment of ES cell DNA at a unique $B g l$ II site downstream of the $\beta^{\text {min }}$ gene. The first fragment was an XhoI-SalI fragment from pMC1NeopA (24); it was inserted in a transcriptional orientation opposite to that of $\beta^{\mathrm{min}}$. The second fragment was inserted downstream of the neo gene in the same orientation as $\beta^{\mathrm{min}}$; it contains a portion of a human HPRT minigene referred to below as $\triangle H P R T$. $\triangle H P R T$ is a 7.6-kb Bam HI fragment from pNI $1 \Delta \mathrm{c}, 2$ (16); it lacks a promoter and exon 1.

Two $\beta$-globin deletion plugs were made. One, $\beta \Delta$ plug6.9, has $6.9 \mathrm{~kb}$ of plug-socket overlap in the HPRT minigene. It consists of (i) a 1.6-kb BamHI-HindIII fragment from upstream of the BALB/c $\beta^{\text {maj }}$ gene; (ii) a $1.2-\mathrm{kb} B g l \mathrm{lI}-H$ indIII fragment from downstream of the $\mathrm{BALB} / \mathrm{c} \beta^{\mathrm{min}}$ gene (this fragment is not relevant to the experiments described here); and (iii) a 7.4-kb ClaI-HindIII portion of the human HPRT minigene, referred to below as HPRT $\Delta 6.9$, which contains the promoter, exons 1 and 2 of the $H P R T$ minigene, and $6.9 \mathrm{~kb}$ of overlap with $\triangle H P R T$. All three fragments are in the same transcriptional orientation.

The other $\beta$-globin deletion plug, $\beta \Delta$ plug1.5 (see Fig. 4), has $1.5 \mathrm{~kb}$ of plug-socket overlap in the HPRT minigene. It consists of (i) a 3.9-kb BamHI-HindIII fragment from just upstream of the BALB/c $\beta^{\text {maj }}$ gene and (ii) a 1.9-kb ClaI-XhoI fragment, referred to below as HPRT $\Delta 1.5$, containing the promoter and exon 1 of the HPRT minigene from pNI1,2 (16). All three fragments are in the same transcriptional orientation.

A $\beta$-globin replacement plug, $\beta^{\text {s }}$ plug1.5 (see Fig. 6), was derived from $\beta \Delta$ plug1.5 by inserting a $5.7-\mathrm{kb}$ HindIII-XbaI fragment of human $\beta^{s}$ globin DNA just upstream of the
HPRT $\Delta 1.5$ fragment and in the same transcriptional orientation.

Cell culture and electroporation. Electroporations were performed on the HPRT-deficient embryonic stem cell line E14TG2a (8). In one case, we used a subclone designated BK4 which was obtained by dilution cloning from the strain E14TG2a (a gift from Beverly H. Koller, University of North Carolina at Chapel Hill). These cell lines were maintained on irradiated mouse embryonic fibroblasts as described previously (10).

Linearized targeting constructs were introduced into ES cells in a 5-mm-long, $100-\mathrm{mm}^{2}$ cross-section chamber by electroporation with a $250-\mu \mathrm{F}$ capacitor charged to $300 \mathrm{~V} ; 2 \times$ $10^{7}$ to $4 \times 10^{7}$ cells were electroporated with DNA at a 4 to 5 $\mathrm{nM}$ concentration. The constructs $\beta \Delta \mathrm{C}, \beta \Delta$ plug6.9, $\beta$ socket, $\beta \Delta$ plug1.5, and $\beta^{\text {s }}$ plug1.5 were linearized with SacII, NotI, NotI, $X b a \mathrm{I}$, and $X b a \mathrm{I}$, respectively. The $\beta \Delta \mathrm{C}$ construct was introduced into E14TG2a cells, and the $\beta$ socket construct was introduced into the BK4 subclone of E14TG2a. The plug constructs were introduced into cell line B20 (see below) which contains an appropriately targeted socket. B20 was expanded and preserved by freezing to provide cells for many targeting electroporations and for tests of its capability of contributing to the mouse germ line.

Preparation and analysis of genomic DNA. PCR was used to screen for targeting of $\beta \Delta C$ as described previously $(9,18)$. DNA for Southern analyses was extracted from ES cells grown in 24-well plates without feeder layer cells. Five probes were used in Southern analyses. The $\beta 1.2$ probe (see Fig. 2) was made by PCR with genomic DNA from a strain $129 / \mathrm{SvJ}$ mouse as the template and primers $5^{\prime}$ AACCCAGGAGGTGCCC ATCA $3^{\prime}$ and 5' CCAGATTTGTGAGCTCAGGG 3'. The NEO probe (see Fig. 2) was made by isolation of a $1.1-\mathrm{kb}$ XhoI-SalI fragment from pMC1NeopA (24). The HPRT 0.3 (see Fig. 2) and HPRT 0.5 (see Fig. 4) probes are, respectively, a $0.3-\mathrm{kb}$ XhoI-HindIII fragment and a $0.5-\mathrm{kb}$ ClaI-BamHI fragment from pNI $1 \Delta c, 2(16)$. The $\beta$ IVS2 probe (see Fig. 6) is a human-specific $\beta$-globin probe described previously (19); it is a 920-bp BamHI-EcoRI fragment from the second intron of human $\beta$-globin.

\section{RESULTS AND DISCUSSION}

Plug and socket strategy. The general scheme for the plug and socket strategy is illustrated in Fig. 1. In the first step of this two-step procedure, conventional gene targeting is used to insert a construct that we call a socket near the gene to be altered. A socket consists of a functional positively selectable marker (M1) and a nonfunctional portion of a different positively selectable marker $(\Delta \mathrm{M} 2)$. ES cell clones made drug resistant by $\mathrm{M} 1$ are screened by Southern analysis or PCR to identify clones containing the correctly targeted socket. A few of these clones are expanded to provide cells for repeated targeting with many different constructs. In the second step of the procedure, a vector that we call a plug alters the locus containing the socket and supplies the missing portion of the positively selectable marker M2. To accomplish this, the plug contains mouse DNA sequences from the gene to be altered and a nonfunctional portion of the second marker (M2 $\Delta$ ) which overlaps $\Delta \mathrm{M} 2$. Recombination between $\Delta \mathrm{M} 2$ and $\mathrm{M} 2 \Delta$, mediated by their shared homology, reconstructs a functional M2. The two positively selectable markers, 1 and 2, must be different (for example, hyg and neo or neo and HPRT) but are otherwise not constrained. The two nonfunctional versions of M2, M2s and $\Delta \mathrm{M} 2$, should have nonrevertible but complementary mutations, preferably deletions. Since the plug and 
A)

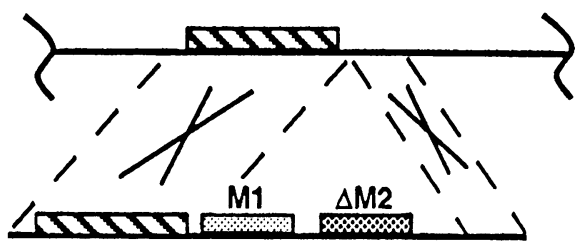

Step 1: select for $M 1$

B)

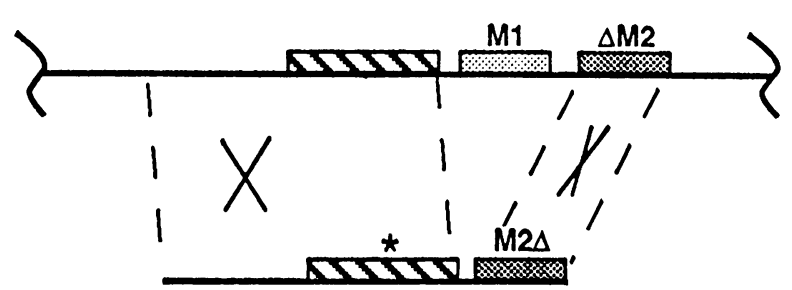

Step 2: select for $M 2$ and screen for loss of M1

C)

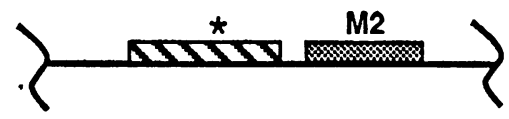

FIG. 1. Schematic diagram illustrating the plug and socket strategy. The gene to be altered is shown as a cross-hatched box, and the two selectable marker genes are shown as stippled boxes. The first step involves insertion of the socket targeting construct containing a functional marker gene (M1) and a different nonfunctional marker gene $(\Delta M 2)$ flanked by homology to the target area. Homologies are indicated by connecting dashed lines with each crossover shown as an $\mathrm{X}$. Insertion of the socket in the first step requires selection for M1 and screening for and cloning of an ES cell line containing the socket at the target locus. The second step involves the completion of the nonfunctional M2 gene by recombination between the socket in the ES cell genome and the plug targeting construct. The plug contains homology to the target locus and a different nonfunctional portion of M2 (M2 which overlaps $\Delta \mathrm{M} 2$. The desired change is represented by an asterisk. The second step requires selection for a functional M2 and screening for the loss of M1. (A) Recombination event to insert the socket. The upper line represents the gene to be modified in the chromosome, and the lower line shows the socket targeting construct. (B) Recombination event to alter the gene and complete M2. The upper line represents the socket in the mouse chromosome, and the lower line represents the plug targeting construct. (C) The desired change in the chromosome of the ES cell.

socket steps are independent events, different plugs can be used to make different modifications starting with the same cell line which contains an appropriately targeted socket.

Specific socket insertion $3^{\prime}$ of the mouse $\beta$-globin locus. We have used the mouse adult $\beta$-globin locus to test the plug socket strategy and to produce valuable ES cell mutants. The socket-containing construct, $\beta$ socket (Fig. 2), was electroporated into the BK4 subclone of E14TG2a cells which lack HPRT function due to a deletion of part of the endogenous Hprt gene (8). M1 in this construct is the neo gene; $\Delta \mathrm{M} 2$ is $\triangle H P R T$, part of an HPRT minigene (see Materials and Methods). After G418 selection for clones containing the neo gene, we screened 189 colonies for alterations in their restriction patterns (Fig. 2) by Southern analysis. Probe $\beta 1.2$, which has homology to both $\beta^{\text {maj }}$ and $\beta^{\text {min }}$, will detect a 10.3-kb EcoRI restriction fragment diagnostic of correct targeting. Figure 3A shows data from eight of the G418-resistant clones; clone 1 has the $10.3-\mathrm{kb}$ band expected from a correctly targeted cell. The other two bands, at 15 and $7.3 \mathrm{~kb}$, are from the other adult $\beta$-globin genes in the ES cell genome that are not modified by the targeting event. The frequency of gene targeting for the introduction of the socket is shown in Table 1.

One of the putatively targeted ES cell lines, B20, was analyzed further to confirm correct insertion of the socket. Southern analysis of B20 with the NEO probe in Fig. 3B shows the expected fragment sizes for the correctly modified locus. The two bands of unequal intensity in the EcoRI lane are expected since the neo gene contains an EcoRI site producing a 13.5-kb and a 10.3-kb fragment with differing amounts of homology to the probe $(0.17 \mathrm{~kb}$ versus $1.0 \mathrm{~kb}$, respectively). Further confirmation of B20 by Southern analysis with the probe HPRT 0.3 is shown in Fig. 3C; this probe was derived from the exons 3 to 6 of human cDNA and has homology to the HPRT minigene as well as to the mouse Hprt gene. The first five lanes of Fig. 3C show that B20 has the expected fragment sizes for a correctly targeted socket. For comparison, the last five lanes of Fig. 3C show the fragments resulting from various digests of unmodified ES cell DNA; these fragments contain exon 3 of the X-linked mouse Hprt gene (15) which has $170 \mathrm{bp}$ of homology to the HPRT 0.3 probe. Fragments corresponding to exons 4 to 6 have less than $80 \mathrm{bp}$ of homology to the probe and are not seen. The expected fragment sizes for the mouse $H p r t$ gene with $X b a \mathrm{I}$ and $E c o \mathrm{RI}$ are 2.2 and $1.3 \mathrm{~kb}$, respectively, which were too small to be included in Fig. 3C.

Proof of the germ line competence of socket ES cells. Since one of our goals for using the plug and socket strategy is to introduce specific mutations into mice, we investigated the ability of B20 to contribute to the mouse germ line. Whenever animals are to be derived, testing the germ line competence of a socket-containing ES cell is clearly valuable prior to its use for the second step of introducing plugs. Tests showed that cell line B20 has a normal number of chromosomes, and injection of the cells into blastocysts yielded chimeras at a normal frequency. One of four chimeras transmitted the ES cell genome to its progeny. These tests consequently establish that the B20 cell line is still pluripotent.

Deletion of the adult $\beta$-globin genes. The presence of mouse $\beta$-globin chains affects the phenotypes of transgenic mice expressing mutant forms of human hemoglobin (17). Although there are some mutations that lower the level of adult hemoglobin in mice $(18,20)$, no null mutation exists for both the adult $\beta$-globin genes, $\beta^{\text {maj }}$ and $\beta^{\text {min }}$. A mouse heterozygous for such a double null mutation would consequently be valuable for breeding to mice harboring human $\beta$-globin transgenes with the aim of subsequently obtaining offspring that depend solely on the transgene for their adult $\beta$-globin. Toward this goal, we constructed a plug that can delete both the $\beta^{\text {maj }}$ and $\beta^{\min }$ genes. This deletion plug, $\beta \Delta$ plug1.5 (Fig. 4), contains 4 $\mathrm{kb}$ of homology upstream of $\beta^{\text {maj }}$ and $1.5 \mathrm{~kb}$ of homology to the socket sequences located downstream of the locus. The desired $\Omega$-type (replacement-type) recombination event shown in Fig. 4 deletes $20 \mathrm{~kb}$ of the ES cell genome (containing the $\beta^{\text {maj }}, \beta^{\text {min }}$, and neo genes) while completing the HPRT minigene.

$\beta \Delta$ plug1.5 was linearized and introduced into the socketcontaining ES cell line B20 in five separate electroporations. Six hypoxanthine-aminopterin-thymidine (HAT)-resistant colonies were obtained. These colonies were expanded, and Southern analysis was performed (Fig. 5). In Fig. 5A we show $X b a$ I fragments hybridizing to the HPRT 0.5 probe; this probe hybridizes to the promoter of the neo gene and to the HPRT 

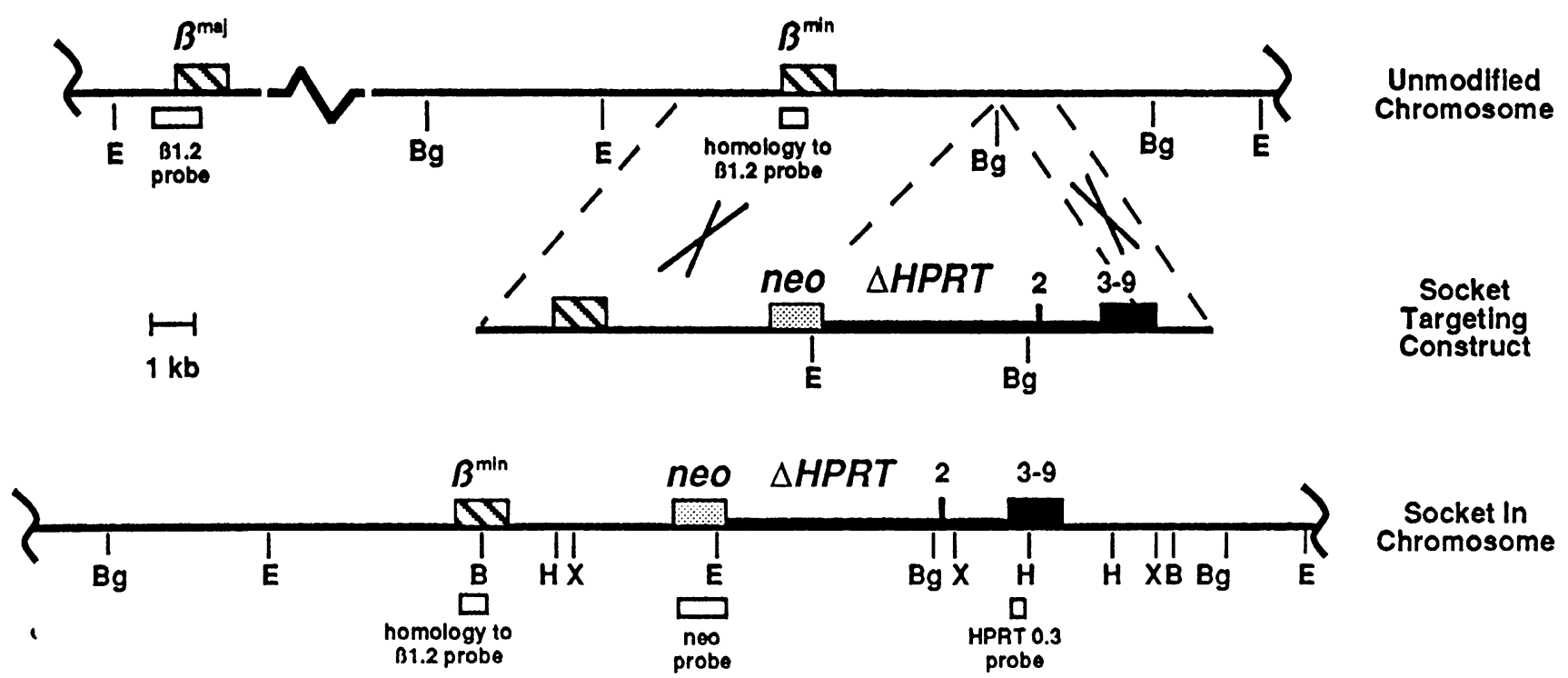

FIG. 2. Target locus, socket-containing targeting construct (ßsocket), and the chromosome resulting from insertion of the socket downstream of the $\beta$-globin locus. Representations are as in Fig. 1, with the following additions. The stippled box represents the neo gene, thick lines indicate $H P R T$ introns, and black boxes represent HPRT exons. Relevant restriction sites for Bam HI (B), BglII (Bg), Eco RI (E), HindIII (H), and XbaI $(\mathrm{X})$ are shown. Various probes are shown as open boxes.

minigene (Fig. 4). Lane $\mathrm{S}$ of Fig. 5A shows an 8.9-kb $X b a \mathrm{I}$ fragment containing the neo gene in DNA from the B20 socket-containing ES cells. The next six lanes $(\Delta \mathrm{P} 1$ to $\Delta \mathrm{P} 6)$ contain digests of DNA isolated from the six HAT-resistant colonies following introduction of the deletion plug. One of these clones $(\Delta \mathrm{P} 1)$ gives a $13-\mathrm{kb} \mathrm{XbaI}$ fragment (Fig. 5A) that corresponds to the desired deletion. This same clone also gives a 12.4-kb HpaI fragment (Fig. 5B) that is likewise diagnostic of the desired targeting event. The other five colonies were correctly targeted to the HPRT portion of the socket-containing $\beta$-globin locus but not to the portion of the locus upstream of the $\beta^{\text {maj }}$ gene, as discussed below in relation to alternate recombination pathways. Distinction between the two types of targeted clone is readily made by testing the HAT-resistant colonies for G418 resistance: correctly targeted colonies are resistant to HAT but sensitive to G418, and incorrectly targeted clones are resistant to both selective agents. A compilation of data from these electroporations is provided in Table 1.

Replacement of the adult mouse genes with human $\beta^{\text {s. }}$. Toward the goal of correctly expressing a targeted human $\beta$-globin variant in a mouse, we constructed a plug targeting vector, $\beta^{\mathrm{s}}$ plug1.5, containing the human $\beta^{\mathrm{s}}$ gene. As shown in Fig. 6 , the $\beta^{\mathrm{s}}$ plug1.5 vector is designed to replace the $\beta^{\text {maj }}$, $\beta^{\text {min }}$, and neo genes with a 5.7-kb HindIII-XbaI fragment containing the human $\beta^{\mathrm{s}}$-globin gene. $\beta^{\mathrm{s}}$ plug1.5 also has two features designed to ensure that the human $\beta^{\mathrm{s}}$ gene will express correctly. First, to avoid promoter competition (2), the plug deletes all known regulatory sequences for both $\beta^{\text {maj }}$ and $\beta^{\text {min }}$, with the exception of the mouse locus control region (4, $5,13)$. Second, the plug contains human $\beta^{\text {s }}$ gene sequences already known to express correctly in transgenic mice (2).

Three electroporations with $\beta^{\mathrm{s}}$ plug1.5 yielded two HATresistant colonies. One of them was sensitive to G418 and was therefore expected to be correctly targeted; the other was resistant and was expected to be incorrectly targeted. Southern blot analyses of these colonies, illustrated in the last two lanes of Fig. 5A and in Fig. 5C, confirm these expectations. The HAT-resistant, G418-sensitive clone $\beta^{\text {sP } 2}$ has a 19-kb XbaI

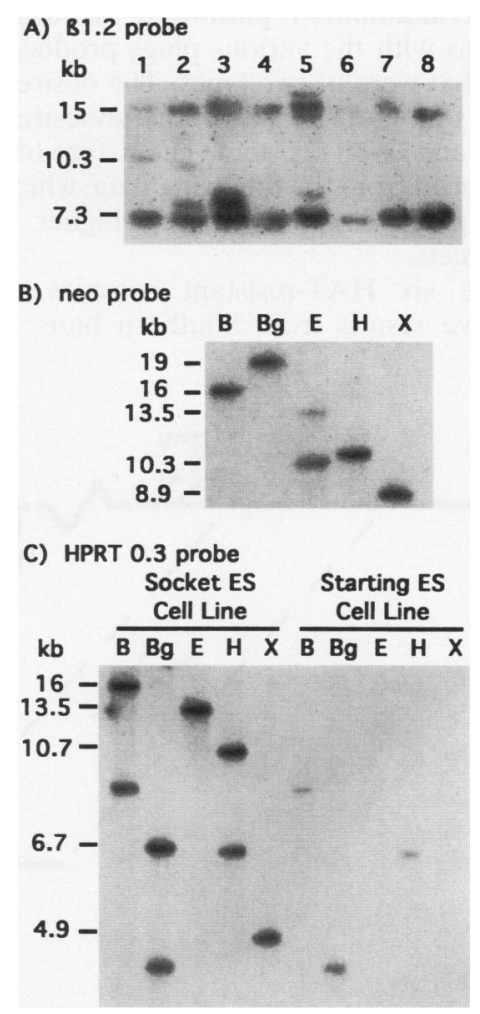

FIG. 3. Southern blot analysis to detect correct insertion of the socket downstream of the mouse $\beta$-globin locus. Probes, expected fragment sizes, and abbreviations are as for Fig. 2. (A) Southern blots using the probe $\beta 1.2$ with EcoRI digests of DNA from G418-resistant ES cell clones after introduction of the socket targeting construct, Bsocket. (B) Southern blots using the NEO probe with various digests of B20 ES cell DNA. (C) Southern blots using the HPRT 0.3 probe with various digests of DNA from clone B20 (first five lanes) and from the starting cell line E14TG2a (last five lanes). 
TABLE 1. Targeting frequency data

\begin{tabular}{|c|c|c|c|c|c|c|c|c|c|c|c|c|c|}
\hline \multirow[b]{2}{*}{$\begin{array}{l}\text { Targeting } \\
\text { construct }\end{array}$} & \multirow{2}{*}{$\begin{array}{c}\text { No. of } \\
\text { electro- } \\
\text { porations }\end{array}$} & \multirow{2}{*}{$\begin{array}{l}\text { Total no. of } \\
\text { cells electro- } \\
\text { porated } \\
\left(10^{7}\right)\end{array}$} & \multirow{2}{*}{$\begin{array}{l}\text { No. of } \\
\text { resistant } \\
\text { colonies }\end{array}$} & \multirow{2}{*}{$\begin{array}{c}\text { No. of } \\
\text { clones } \\
\text { screened }\end{array}$} & \multicolumn{2}{|c|}{$\begin{array}{l}\text { No. of clones } \\
\text { targeted }\end{array}$} & \multicolumn{2}{|c|}{$\begin{array}{c}\text { Total homology } \\
(\mathrm{kb})\end{array}$} & \multicolumn{2}{|c|}{$\begin{array}{l}\text { Total targeting } \\
\text { frequency }\end{array}$} & \multicolumn{3}{|c|}{$\Omega$-type frequency } \\
\hline & & & & & $\Omega$ type & O type & $\Omega$ type & O type & Per cell & $\begin{array}{l}\text { Per } \\
\text { resistant } \\
\text { colony } \\
(\%)\end{array}$ & Per cell & $\begin{array}{c}\text { Per } \\
\text { resistant } \\
\text { colony } \\
(\%)\end{array}$ & $\begin{array}{c}\text { Per HAT } \\
\text { G418 } \\
\text { (\%) colony } \\
(\%)\end{array}$ \\
\hline$\beta \Delta C$ & 5 & 10 & $893^{a}$ & $600^{b}$ & 0 & $\mathrm{NA}^{c}$ & 4.7 & NA & 0 & 0 & 0 & 0 & $\mathrm{NA}^{e}$ \\
\hline Bsocket & 2 & 6 & $1,035^{d}$ & 189 & 17 & NA & 8.0 & NA & $1.5 \times 10^{-6}$ & 9.0 & $1.5 \times 10^{-6}$ & 9.0 & NA \\
\hline$\beta \Delta$ plug1.5 & 5 & 15 & $6^{e}$ & 6 & 1 & 4 & 5.5 & 1.5 & $3.3 \times 10^{-8}$ & 83 & $6.6 \times 10^{-9}$ & 17 & 100 \\
\hline$\beta \Delta$ plug6.9 & 2 & 6 & $40^{e}$ & 38 & 0 & 38 & 8.5 & 8.1 & $6.7 \times 10^{-7}$ & 100 & 0 & 0 & $\mathrm{ND}^{f}$ \\
\hline$\beta^{\mathrm{s}}$ plug1.5 & 3 & 9 & $2^{e}$ & 2 & 1 & 1 & 5.5 & 1.5 & $2.2 \times 10^{-8}$ & 100 & $1.1 \times 10^{-8}$ & 50 & 100 \\
\hline
\end{tabular}

${ }^{a} \mathrm{G} 418$ and ganciclovir selection.

${ }^{b}$ Equivalent to 6,000 colonies resistant to G418 alone.

${ }^{c}$ NA, not applicable.

${ }^{d} \mathrm{G} 418$ selection.

${ }^{e}$ HAT selection.

${ }^{f} \mathrm{ND}$, not determined.

fragment hybridizing to the HPRT 0.5 probe and a $10-\mathrm{kb}$ NdeI fragment hybridizing to the human-specific $\beta I V S 2$ probe; these fragments are of the sizes expected for the correct replacement targeting (Fig. 6). The HAT-resistant, G418-resistant colony does not give fragments of the expected sizes and is therefore incorrectly targeted, and we show below that it is the result of a complex event. A compilation of data from electroporations with $\beta^{\mathrm{s}}$ plug1.5 is presented in Table 1 .

Alternate recombination pathways. As described above, electroporations with the various plugs produced HAT-resistant colonies that were of two types. The desired colonies are HAT resistant and G418 sensitive; the undesired colonies are HAT resistant and G418 resistant. The nature of the undesired event was deduced from the following data, which also allowed us to design plug vectors yielding a higher proportion of desirable products.

Five of the six HAT-resistant colonies obtained with $\beta^{\mathrm{s}} \Delta$ plug1.5 gave results from Southern blots that were not consistent with the desired $\Omega$-type recombinational event. For example, Fig. $5 \mathrm{~A}$ shows that clones $\Delta \mathrm{P} 3$ and $\Delta \mathrm{P} 5$ have two $X b a \mathrm{I}$ bands $(7.6$ and $10 \mathrm{~kb})$ instead of the expected $13-\mathrm{kb}$ band. These fragments are, however, readily interpreted as being the consequence of an O-type (insertion-type) recombinational event in which the plug construct first recircularized and then recombined as shown in Fig. 7. Clones $\Delta \mathrm{P} 4$ and $\Delta \mathrm{P} 6$ show only one $X b a I$ band, at $17 \mathrm{~kb}$, indicating that loss of the $X b a I$ site in the plug construct had occurred prior to recombining in an O-type reaction. Southern analysis with other restriction digests supports the view that $\Delta \mathrm{P} 3$ through $\Delta \mathrm{P} 6$ are products of O-type reactions (data not shown). One clone $(\Delta \mathrm{P} 2)$ showed no change in the size of the $X b a I$ fragment from the socket downstream of $\beta$-globin. This clone had, however, an additional BamHI fragment, indicating that the $\mathrm{X}$-linked mouse Hprt locus was now wild type (data not shown). We suspect that this clone $\Delta \mathrm{P} 2$ resulted from the acquisition of mouse $\mathrm{Hprt}$ sequences derived from the wild-type embryonic fibroblast


Chromosome After Deletion

FIG. 4. The socket-containing chromosome, the linearized plug targeting construct for deletion, and the chromosome obtained after deletion. Representations are as in Fig. 2, with the following additions: (i) the thick broken line of the targeting construct represents plasmid sequences, and (ii) $\mathrm{Hp}$ and $\mathrm{X}$ represent $\mathrm{HpaI}$ and $\mathrm{XbaI}$ restriction sites, respectively. 
A) HPRT 0.5 probe

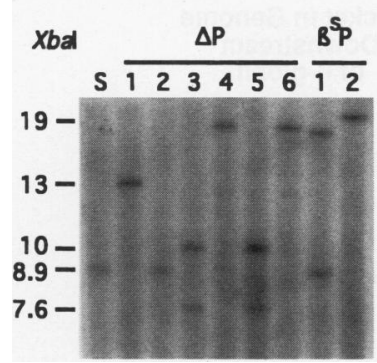

B) HPRT 0.5 probe

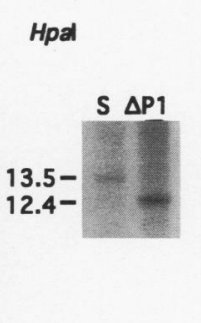

C) BIVS2 probe Ndel $B^{5} \mathbf{P}$ 12 $11=-$
$10=-$
FIG. 5. Southern blot analysis of HAT-resistant ES cell clones after introduction of plugs. (A) Southern blot with the probe HPRT 0.5 of $X b a$ I-digested DNA. Lane $S$ was with DNA from the socket ES cell line $\mathrm{B} 20$. Lanes $\triangle \mathrm{P} 1$ (deletion plug clone 1) through $\triangle \mathrm{P} 6$ contain DNA from six HAT-resistant ES cell lines isolated after introduction of $\beta \Delta$ plug1.5; the expected sizes and probes are shown in Fig. 4. Lanes labeled $\beta^{\text {sP }}$ ( $\beta^{\mathrm{s}}$ plug) represent two ES cell lines derived after introduction of $\beta^{\mathrm{s}}$ plug1.5; the expected sizes and probes are shown in Fig. 6. (B) Southern blot using the probe HPRT 0.5 with HpaI-digested DNA from $S$ (socket cell line B20) and $\triangle \mathrm{P} 1$ (HAT-resistant clone 1 derived from introduction of the $\beta \Delta$ plug1.5). (C) Southern blot using the probe $\beta I V S 2$ with NdeI-digested DNA from two HAT-resistant ES cell lines (1 and 2$)$ from introduction of $\beta^{\mathrm{s}}$ plug1.5; the expected sizes and probes are shown in Fig. 6.

feeder layer cells present during electroporation of the plug, although the Southern blots showed no evidence that the Hprt deletion on the $\mathrm{X}$ chromosome in $\Delta \mathrm{P} 2$ (or in any of the other clones) had been corrected by the plug.

Electroporation of $\beta^{\mathrm{s}}$ plug1.5, as described above, gave one HAT-resistant colony ( $\beta^{\text {sP1 }}$ ) which was not the desired $\Omega$-type event. Southern blot analysis of DNA from this colony revealed an 8.9-kb and a 16.9-kb XbaI band (Fig. 5). These bands could be the result of two independent events: (i) a spontaneous recombination event resulting in both homologs of chromosome 7 having a socket and (ii) the insertion of a portion of the plug targeting construct (after a 6.9-kb deletion that removed the $X b a I$ linearization site) to one of the two sockets via an O-type recombinational event.

The foregoing analyses indicate that $\mathrm{O}$-type crossing over within the $\triangle H P R T$ portion of the target locus can occur without crossing over in the $\beta$-globin portion. We reasoned, therefore, that use of a relatively short stretch of homology between $H P R T \Delta$ and $\triangle H P R T$ should reduce the chances of this type of event, since the initial targeting would likely be mediated by the much longer stretch of homology in the $\beta$-globin portion. This argument receives considerable support from our observation (Table 1$)$ that a plug ( $\Delta \beta$ plug6.9) with a 6.9-kb stretch of HPRT overlap gave approximately 30 times more of the O-type events than were seen with the $1.5-\mathrm{kb}$ stretch of overlap. In general, therefore, it is better to drive the second event step in the plug and socket system with large amounts of upstream homology while limiting the HPRT overlap. Further studies are needed to find the optimal length, which may be less than the $1.5 \mathrm{~kb}$ currently used. In any case, the proportion of desired colonies is so high (two of seven in the experiments with $1.5 \mathrm{~kb}$ of overlap) that a simple screen for sensitivity to G418 can be used to eliminate the unwanted O-type events.

Overall frequencies of gene targeting. Table 1 summarizes the data obtained with several different targeting constructs. These data show that of the 46 HAT-resistant colonies analyzed from three plug constructs $(\beta \Delta$ plug1.5, $\beta \Delta$ plug6.9, and $\beta^{\text {s }}$ plug1.5), 45 colonies were targeted. The one colony that was an exception was probably the result of the transfer of an Hprt gene from the feeder layer to the ES cell during electroporation. Therefore, for all practical purposes, the plug and socket method has eliminated background colonies which were not the result of gene targeting. However, there are two types of targeting event that result from the introduction of a plug. One of these is the desired $\Omega$-type event, and the other is the undesired O-type event. This background of undesired events can be reduced substantially by reducing the amount of $H P R T$ homology in the plug, and this background is eliminated by
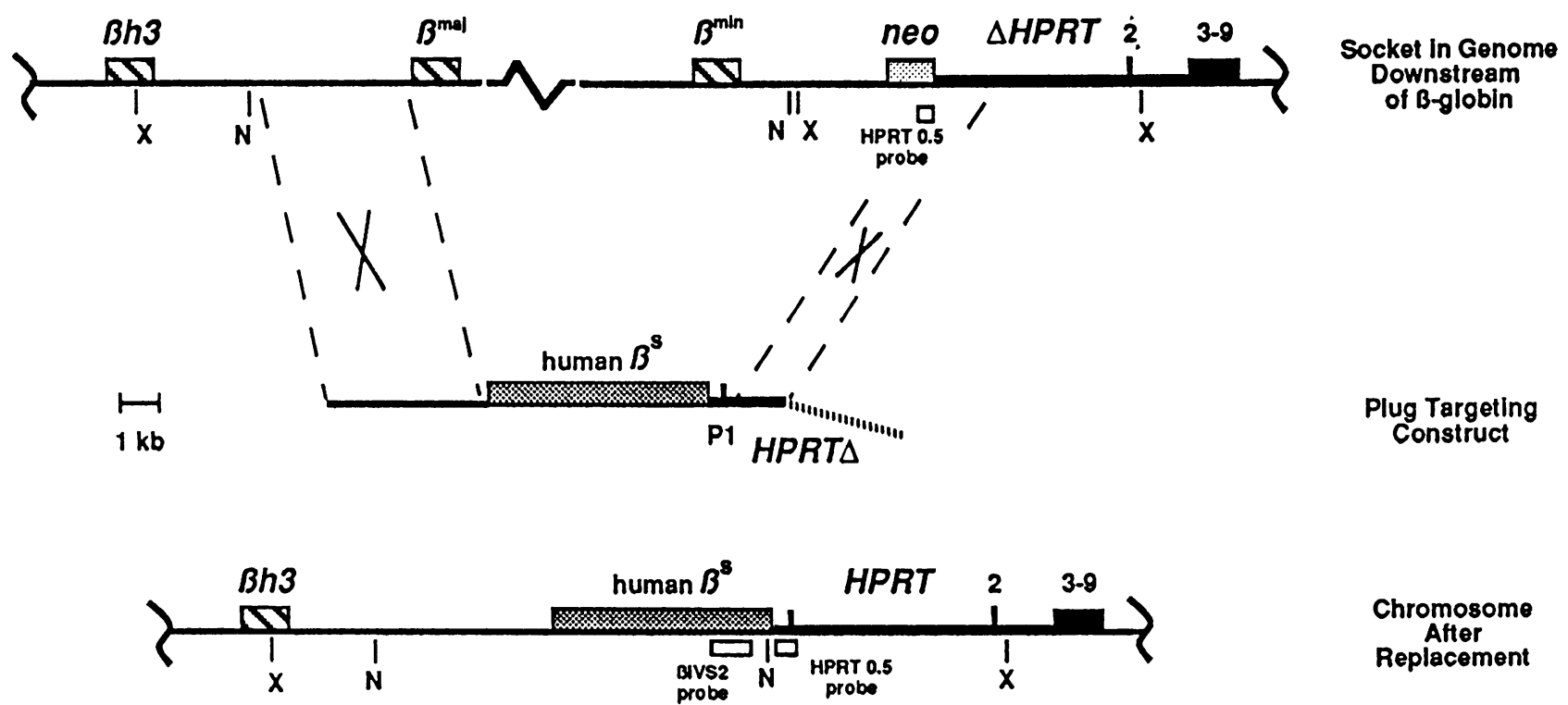

FIG. 6. The socket-containing chromosome, the linearized plug targeting construct for insertion of human $\beta^{\mathrm{s}}$ globin, and the chromosome obtained after insertion. Representations are as in Fig. 2, with the following additions: (i) the thick broken line of the targeting construct represents plasmid sequences; and (ii) $\mathrm{N}$ and $\mathrm{X}$ represent $\mathrm{NdeI}$ and $\mathrm{XbaI}$ restriction sites, respectively. 


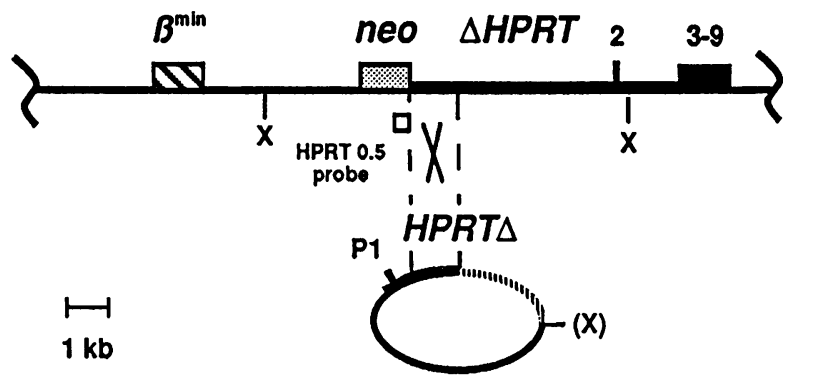

\section{Socket In Genome Downstream of B-globin}

Plug Targeting Construct

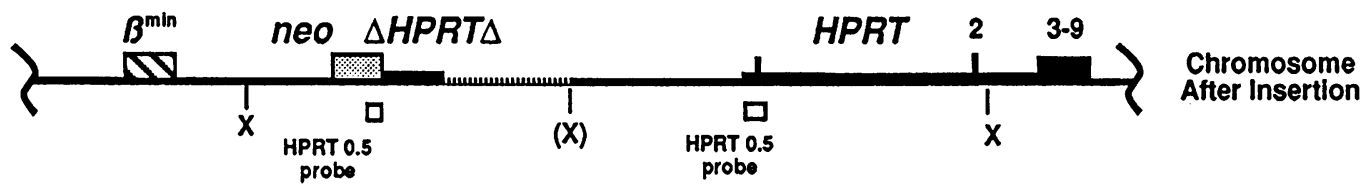

FIG. 7. The socket-containing chromosome, the recircularized $\beta \Delta$ plug1.5 targeting construct, and the chromosome after an O-type recombination. The recircularized $\beta \Delta$ plug1.5 inserts into the socket ES cell genome by a single crossover within the HPRT sequences. The resulting chromosome contains all original socket chromosome sequences as well as the sequences of the plug targeting construct, thus creating a duplication of a portion of the HPRT sequences as well as a functional HPRT gene. Symbols are described in the legend to Fig. 2.

screening for G418 sensitivity. Thus, the two plugs with $1.5 \mathrm{~kb}$ of $H P R T$ homology ( $\beta \Delta$ plug1.5 and $\beta^{\text {s }}$ plug1.5) yielded seven HAT-resistant colonies, of which two were G418 sensitive; both of these colonies were the desired $\Omega$-type events.

We have also included in Table 1 , for comparison, data obtained from a conventional targeting construct, $\beta \Delta \mathrm{C}$. This construct has the neo gene between a $0.8-\mathrm{kb}$ region of homology $5^{\prime}$ to the $\beta^{\text {maj }}$ gene and a 3.9-kb region of homology $3^{\prime}$ to the $\beta^{\text {min }}$ gene. Although this homology differs from that used in $\beta \Delta$ plug1.5 (3.9 kb of homology $5^{\prime}$ to $\beta^{\text {maj }}$ and $1.5 \mathrm{~kb}$ with the incomplete $H P R T$ minigene $3^{\prime}$ to $\beta^{\mathrm{min}}$ ), these constructs have many similarities, including the following: (i) both have the potential to delete approximately $20 \mathrm{~kb}$ including both adult $\beta$-globin genes, (ii) the origin of the homology for both constructs was BALB/c DNA, and (iii) the lengths of homology were similar ( $4.7 \mathrm{~kb}$ for $\beta \Delta \mathrm{C}$ and $5.5 \mathrm{~kb}$ for the two plugs). However, screening the equivalent of 6,000 G418-resistant clones by PCR failed to yield any targeted colonies with $\beta \Delta C$. Thus, we estimate that screening is reduced more than 1,000fold by use of the plug and socket strategy.

Frequencies of gene targeting per cell electroporated vary depending on many factors. A typical frequency for a conventional gene targeting experiment is approximately one targeted cell per 2 million electroporated cells (3). The two plugs $\beta \Delta$ plug1.5 and $\beta^{\mathrm{s}}$ plug1.5 targeted at an approximately 17 -foldlower frequency (one targeted cell per 34 million cells), possibly as a result of the use in the targeting constructs of DNA from a strain of mouse not isogenic to the ES cell strain $(6,7,23)$. Yet despite this lower rate of targeting per cell, the positive selection inherent to the plug and socket procedure allowed us to recover the desired events with minimal effort. This ability to isolate correctly targeted cells even with vectors not maximized for their efficiency emphasizes the power of using a recombination-dependent positive selection for the second step. It is this use of a recombination-dependent positive selection that distinguishes our present system from repeated targeting strategies previously reported $(1,22,26)$.

Limitations of the procedure. The major limitation of the plug and socket procedure is that the positively selectable marker (the HPRT minigene) remains near the target locus at the end of the experiment. The degree to which this is important will vary in different instances, but the effects of the residual marker can always be ascertained, if this is necessary, by carrying out a control targeting experiment with a plug that causes no changes in the target locus itself. The product of this control experiment (a plug and socket next to the wild-type locus) will provide a baseline against which all the other mutations can be evaluated.

Comparison with other repeated targeting strategies. Several other two-step strategies for repeated targeting have been described. All rely on negative selection to isolate clones that have lost a marker $(1,22,26)$. Briefly, these procedures use conventional gene targeting to introduce a negatively selectable marker to a specific location in the genome as a first step. In the second step, a different gene targeting construct is used to introduce a mutation to the same site while simultaneously removing the negatively selectable marker. Selection against this marker is used to isolate the targeted clones. Since the loss of marker function can occur by events other than homologous recombination, these strategies generally give a background of resistant clones that are not targeted. Nevertheless, these methods have the advantage of not leaving any marker sequence at the targeted locus once they are completed and can therefore be used at any position within the locus. The ratio between the loss of the selectable marker by nontargeted events to its loss by homologous recombination determines whether the desired recombinants will be recoverable from the background of untargeted clones.

Other applications. In general, the procedure that we have described is most useful for carrying out series of experiments in which a target locus is to be modified systematically. The ease with which we achieved two large changes at the mouse $\beta$-globin locus exemplifies one such application. Another series might include a variety of small mutations in the promoter of a target gene, with the caveat that the mutants would have to be compared against a control in which the wild-type gene and promoter had the reconstituted HPRT minigene upstream.

Possible alterations. We described above how differentiating between $O$ - and $\Omega$-type recombination events can be achieved simply by a screen for G418 sensitivity. This genetic screen could readily be changed to genetic selection. For example, the HSV $t k$ gene could be introduced into the plug construct outside the region of homology. The $\Omega$-type recombinants would lack the HSV $t k$ gene and be resistant to 
ganciclovir, whereas the O-type recombinants would retain the HSV $t k$ gene as a consequence of recircularization and would be sensitive to ganciclovir (14).

We chose the HPRT gene as the second selectable marker in our present applications of the plug and socket strategy because HAT selection is rapid and efficient. In addition, subsequent removal of the HPRT gene can be accomplished, if necessary, by a third gene targeting event using 6-thioguanine selection. A disadvantage of using the $H P R T$ gene is that the parent ES cell line must be HPRT deficient. Other markers might be used in its place. For example, the $\Delta$ neo and neos gene pair devised by Kucherlapati et al. (11) would be a good candidate for an alternate second marker with the hyg gene as the first marker.

Future work. Mice generated now or in the future from all three ES cell lines made in the present experiments should prove useful for other studies. Animals already generated from the B20 ES line carry the $\triangle H P R T$ socket, which will make them useful for future tests of targeting the $\beta$-globin locus in bone marrow stem cells by using HAT selection. Animals generated from the ES cells having deletion of the $\beta^{\text {maj }}$ and $\beta^{\text {min }}$ genes could be mated with mice transgenic for the human $\beta^{\mathrm{s}}$ gene to derive better mouse models of sickle cell anemia. Animals generated from the ES cells having the human $\beta^{\text {s }}$ gene in place of the two mouse adult $\beta$-globin genes could be mated with comparable mice expressing human $\alpha$-globin genes to derive a mouse model of sickle cell anemia in which no adult mouse hemoglobins are present.

\section{ACKNOWLEDGMENTS}

This work was supported by National Institutes of Health grants GM20069 and HL37001.

We thank Annette Staton, Denise Lee, Kimberly Kluckman, John Hagaman, and Sylvia Hiller for technical assistance; the SmithiesMaeda laboratory group (in particular Sarah Bronson) for helpful discussions; and Laura Reid and Beverly Koller for strains and plasmids.

\section{REFERENCES}

1. Askew, G. R., T. Doetschman, and J. B. Lingrel. 1993. Sitedirected point mutations in embryonic stem cells: a gene-targeting tag-and-exchange strategy. Mol. Cell. Biol. 13:4115-4124.

2. Behringer, R. R., T. M. Ryan, M. P. Reilly, T. Asakura, R. D. Palmiter, R. L. Brinster, and T. M. Townes. 1989. Synthesis of functional human hemoglobin in transgenic mice. Science 245: 971-973.

3. Capecchi, M. R. 1989. Altering the genome by homologous recombination. Science 244:1288-1292.

4. Charnay, P., P. Mellon, and T. Maniatis. 1985. Linker scanning mutagenesis of the $5^{\prime}$-flanking region of the mouse beta-majorglobin gene: sequence requirements for transcription in erythroid and nonerythroid cells. Mol. Cell. Biol. 5:1498-1511.

5. Cowie, A., and R. M. Myers. 1988. DNA sequences involved in transcriptional regulation of the mouse beta-globin promoter in murine erythroleukemia cells. Mol. Cell. Biol. 8:3122-3128.

6. Deng, C., and M. R. Capecchi. 1992. Reexamination of gene targeting frequency as a function of the extent of homology between the targeting vector and the target locus. Mol. Cell. Biol. 12:3365-3371.

7. Hasty, P., J. Rivera-Perez, and A. Bradley. 1991. The length of homology required for gene targeting in embryonic stem cells. Mol. Cell. Biol. 11:5586-5591.

8. Hooper, M., K. Hardy, A. Handyside, S. Hunter, and M. Monk. 1987. HPRT-deficient (Lesch-Nyhan) mouse embryos derived from germline colonization by cultured cells. Nature (London) 326:292-295.

9. Kim, H. S., and O. Smithies. 1988. Recombinant fragment assay for gene targeting based on the polymerase chain reaction. Nucleic Acids Res. 16:8887-8903.

10. Koller, B. H., H. S. Kim, A. M. Latour, K. Brigman, R. Boucher, Jr., P. Scambler, B. Wainwright, and O. Smithies. 1991. Toward an animal model of cystic fibrosis: targeted interruption of exon 10 of the cystic fibrosis transmembrane regulator gene in embryonic stem cells. Proc. Natl. Acad. Sci. USA 88:10730-10734.

11. Kucherlapati, R. S., E. M. Eves, K. Y. Song, B. S. Morse, and O. Smithies. 1984. Homologous recombination between plasmids in mammalian cells can be enhanced by treatment of input DNA. Proc. Natl. Acad. Sci. USA 81:3153-3157.

12. Luria, S. E., and M. Delbruck. 1943. Mutations of bacteria from virus sensitivity to virus resistance. Genetics 28:491-511.

13. Macleod, K., and M. Plumb. 1991. Derepression of mouse betamajor-globin gene transcription during erythroid differentiation. Mol. Cell. Biol. 11:4324-4332.

14. Mansour, S. L., K. R. Thomas, and M. R. Capecchi. 1988 Disruption of the proto-oncogene int-2 in mouse embryo-derived stem cells: a general strategy for targeting mutations to nonselectable genes. Nature (London) 336:348-352.

15. Melton, D. W., D. S. Konecki, J. Brennand, and C. T. Caskey. 1984. Structure, expression, and mutation of the hypoxanthine phosphoribosyltransferase gene. Proc. Natl. Acad. Sci. USA 81: 2147-2151.

16. Reid, L. H., R. G. Gregg, O. Smithies, and B. H. Koller. 1990. Regulatory elements in the introns of the human HPRT gene are necessary for its expression in embryonic stem cells. Proc. Natl. Acad. Sci. USA 87:4299-4303.

17. Ryan, T. M., T. M. Townes, M. P. Reilly, T. Asakura, R. D. Palmiter, R. L. Brinster, and R. R. Behringer. 1990. Human sickle hemoglobin in transgenic mice. Science 247:566-568.

18. Shehee, W. R., P. Oliver, and O. Smithies. 1993. Lethal thalassemia after insertional disruption of the mouse major adult betaglobin gene. Proc. Natl. Acad. Sci. USA 90:3177-3181.

19. Shesely, E. G., H. S. Kim, W. R. Shehee, T. Papayannopoulou, O. Smithies, and B. W. Popovich. 1991. Correction of a human beta S-globin gene by gene targeting. Proc. Natl. Acad. Sci. USA 88:4294-4298.

20. Skow, L. C., B. A. Burkhart, F. M. Johnson, R. A. Popp, D. M. Popp, S. Z. Goldberg, W. F. Anderson, L. B. Barnett, and S. E. Lewis. 1983. A mouse model for beta-thalassemia. Cell 34:10431052.

21. Smithies, O., R. G. Gregg, S. S. Boggs, M. A. Koralewski, and R. S. Kucherlapati. 1985. Insertion of DNA sequences into the human chromosomal beta-globin locus by homologous recombination. Nature (London) 317:230-234.

22. Stacey, A., A. Schnieke, J. McWhir, J. Cooper, A. Colman, and D. W. Melton. 1994. Use of double-replacement gene targeting to replace the murine alpha-lactalbumin gene with its human counterpart in embryonic stem cells and mice. Mol. Cell. Biol. 14:10091016.

23. Te Riele, H., E. R. Maandag, and A. Berns. 1992. Highly efficient gene targeting in embryonic stem cells through homologous recombination with isogenic DNA constructs. Proc. Natl. Acad. Sci. USA 89:5128-5132.

24. Thomas, K. R., and M. R. Capecchi. 1987. Site-directed mutagenesis by gene targeting in mouse embryo-derived stem cells. Cell 51:503-512.

25. Weatherall, D. J., J. B. Clegg, D. R. Higgs, and W. G. Wood. 1989. The hemoglobinopathies, p. 2281-2339. In C. R. Scriver, A. L. Beaudet, W. S. Sly, and D Valle (ed.), The metabolic basis of inherited disease, vol. 2 McGraw Hill, New York.

26. Wu, H., X. Liu, and R. Jaenisch. 1994. Double replacement: strategy for efficient introduction of subtle mutations into the murine Colla-1 gene by homologous recombination in embryonic stem cells. Proc. Natl. Acad. Sci. USA 91:2819-2823. 